\title{
Making use of students' digital habits in higher education: What they already know and what they learn
}

\author{
Eva Hansson \\ Halmstad University, Sweden \\ Jeanette Sjöberg \\ Halmstad University, Sweden
}

\section{Abstract}

Varieties of digital practices have increasingly become part of people's everyday lives and people, in general, use these communicative practices on a daily basis, mostly for social and entertaining purposes. As to higher education, researchers have pointed out that digital technology could be a useful tool in how to learn more effectively, if it is based on the abilities that students bring with them into higher education from their everyday life (for example, Buzzard et. al., 2011). In this case study, we explore the issue of students' digital practices in everyday life as well as in higher education, in a teacher training programme at a Swedish University. The aim is two-fold: on the one hand, to provide knowledge regarding students' everyday experiences of digital practices and the ways in which these are utilised in higher education; on the other hand, to contribute to the understanding of the ways in which higher education contributes to challenging and developing students' digital skills. Twenty-nine students from teacher training programmes participated in the study by answering a questionnaire. The results show that the students' digital habits are not being used or acknowledged in higher education, except for when it comes to their Teacher Training Practice (TTP). Furthermore, the results also show that higher education contributes to students' digital skills. This, we argue, could be of interest for teachers and researchers in teacher training programmes and for teachers in primary to tertiary education, in developing education activities with digital technology based on pupils' and students' digital habits. We can also see that the study can inspire other teachers in higher education, where the idea of using students' digital habits perhaps is not yet taken into consideration. 
Keywords: digital technology; higher education; teacher training practice; digital habits; digital skills; digital environment.

\section{Introduction}

'If I lose my cell phone, I lose half my brain' (Teenager in Prensky, 2009, p.2).

One of the concerns of research on digital learning is technology's impact on the learning process itself. In the quotation above, the teenager expresses that the digital device is a part of her body. Could it be that the teenager, because she implies that the mobile phone and the brain belong together, also implies that it is not possible to learn without the digital device? Beaudoin (2006) states that the rapid proliferation of digital technologies will have a dramatic influence on higher education and that it will affect the conventional ways of teaching. In addition, predictions were made that 'new technologies will transform teaching and learning processes from being highly teacher-dominated to student-centred' (GuriRosenblit, 2009, p.5). How should a teacher in higher education relate to digital learning? Are the institutions of higher education successful in arranging and providing learning environments based on the potential of digital media? Often, we find ourselves only incorporating analogue material (compare conventional literacies: Knobel and Lanksher, 2007), in a digital platform and/or Learning Management System (LMS), without considering the expanded potentials available in the digital media. Perhaps the students would rather use Facebook than LMS because the university teacher failed to design the learning task optimally? Previous research shows that students' own experiences of digital practices are not used in higher education (Buzzard et al, 2011; Kelm, 2011; Lichy, 2012). Instead of only using the technology of social and entertaining values, maybe the technology, if it is based on the abilities the student brings into higher education from their daily lives, may be a positive tool in learning more effectively (Buzzard et al, 2011).

\section{Students' digital habits and higher education}

From their childhood, students of today have used other artefacts as well as created knowledge in new ways than earlier generations have done. For Generation $Y$ (persons born between 1982-95, also known as millennials) represented by the teenager above, 
digital technology is a natural component of daily life (Moos \& Honkomp, 2011). One consequence of that is that both teachers and parents today have a notion that students are studying less because they spend a great deal of time on the internet, most commonly on social media or playing online games (O'Brien, 2010). In addition, there is a contemporary global debate concerning the place of mobile phones and other screen devices in schools. In France, for example, mobile phones have been banned up to secondary school. There is also a debate about young people's worsened physical, social and psychosocial health today, related to the extended screen time. In the SEYLE report (Carli et al, 2014) findings showed that a group of pupils who were positive towards the use of Internet/TV/videogames not related to school and work had a sedentary lifestyle and reduced sleep as well as suffered from suicidal thoughts and depression.

On the other hand, there are those who advocate that mobile phones and time in front of other digital devices actually benefit children's learning development. For instance, Neumann and Neumann (2013) suggest that digital tablets have the potential to enhance children's emergent literacy skills. Furthermore, in the latest Programme for International Student Assessment (OECD, 2016) the findings show that boys' reading comprehension on the computer screen, in almost all OECD countries, is relatively better than reading comprehension on paper.

Instead of only using technology for social and entertaining purposes, technology could be a useful tool in how to learn more efficiently if it is based on the abilities that students bring with them into higher education from their everyday life (Buzzard et. al., 2011). When it comes to adults, research shows that students' own experiences of digital practices are not much considered in higher education (for example Buzzard et al, 2011; Kelm, 2011; Lichy, 2012). However, some recent studies point in the opposite direction. For example, Liu (2018) describes social media as a 'potential powerful tool' in higher education and uses Twitter as an example, and Jain and Dutta (2018) argue for the congruency of gamification as a tool for effective learning among the millennial population. Both examples derive from students' experiences of digital tools outside higher education and take into account their everyday use as an origin for further knowledge.

However, university students, regardless of their digital experiences and skills, often encounter pedagogies and teaching structures that still follow traditional approaches, 
referred to as teacher-focused approach to teaching (Entwistle, 2009), where knowledge is seen as something that could be transferred from the teacher to the student. Chen (2008) found that teachers, even though they believed themselves to be following the constructivist learning theory, in reality, had a teacher-based way of teaching with the lecture as a basis. In those cases where they used technology, it was merely used as a support for that kind of teaching. In 2005, Trucano concluded that '[s]tudies on the use of ICTs [information and communication technologies] suggest that despite the rhetoric that ICTs can enable new types of teaching and learning styles, for the most part they are being used to support traditional learning practices' (p.35). Higher education institutions are forced to change since the shift to a more student-centred learning is needed and the globalised twenty-first century skills for work environment are more complex and demanding than before. Educators are today more of facilitators, they are 'no longer the sole authoritative source of information and are expected to assist students in navigating the mastery of content and skills' (Adams Becker et al, 2017).

In the context of teacher training programmes, we note that the traditional pedagogy, teacher-focused and not very digital, is still in place. How can that be? This is probably due to the paradigm shift, where institutions have to take advantage of new technology (Rogers, 2000). As Laurillard expresses it: 'The arrival of digital technology over the past three decades, increasingly impacting on work, leisure, and learning, has been a shock to the education system that it has yet to absorb' (2012, p.2).

An opposite approach is when the students are active participants in the learning process, creating knowledge together with both teachers and other students in learning situations that are purposeful and relevant to the subject: 'This framework suggests that quality learning is achieved when teachers and learners together deal with content in pedagogically suitable ways' (Zepke, 2013, p.98). This approach could be called studentfocused and the knowledge is contextualised (Entwistle, 2009).

\section{The study}

In the study presented here, 29 students from an undergraduate teacher education programme at a small Swedish University participated by answering a questionnaire (see appendix 1). The focus of the study was on the students' digital practices in everyday life 
and in educational situations. By 'digital practices' we mean the different contexts in which students participate in digital media (such as forums, communities) and their use of interactive online and offline games. In our study, there is an interest in both students as actors in relation to their own studies in encounters with digital media and in the knowledge of how students' digital practices in everyday life and in educational situations are utilised and developed during their education.

The research questions were:

- How can students' digital habits be an asset in higher education?

- How can higher education that includes digital practice develop students' digital skills?

\section{Methodology}

In the present study, a questionnaire containing six questions (see appendix 1) was digitally distributed to 269 students in two teacher training programmes during their last spring semester. The reason for this approach was to capture experiences from students who were about to complete their education; hence the chosen method was a case study. Case studies play a significant role in educational and social research (Alnaim, 2015) and are often used to gain knowledge about phenomena related to individuals, groups, and organisations (Yin, 1994).

A mere 29 students answered the questionnaire and their answers were gathered in spread sheet where each respondent received an identification number. The main reason for the relatively small number of participants $(11 \%)$ is most likely due to the fact that the students had almost completed their education and were not motivated to answer, but since this was the target group, that was taken into consideration beforehand. Obviously, such a small sample cannot be generalised in any way. However, the results can still provide important indications within a limited area of interest. In a case study, research aims to explore a contemporary real-life phenomenon within its context through detailed contextual analysis of a limited number of events or conditions and their relationships (Yin, 1984). The 29 students answered individually and could not see each other's answers. Informed consent was obtained (see appendix 2). 


\section{Analysis}

The analysis, which had an inductive approach, contained several steps (1-4):

Step 1: All data was read through several times, with the purpose of getting to know the data (Taylor-Powell \& Renner, 2003) and to identifying patterns. This reading led to the conclusion that the answers to question 1,2 and 3 could be quantified, while the answers to question 4, 5 and 6 (that were open-ended) could not, thus these were separated in the analysis.

Step 2: In working with questions 1, 2 and 3, tables were constructed to illustrate the answers. In the analysis of the answers to the open-ended questions 4, 5 and 6 colour coding was used to identify similarities and differences in the answers. In the process of analysis, three themes were identified: 1. Students' digital habits (questions 1-3); 2. Students' experience of how their digital habits are used in their studies in higher education (questions 4-5); and 3. Students' experience of how their digital habits are developed during their education (question 6).

Step 3: The relative importance of different themes (Taylor-Powell \& Renner, 2003) was assessed by, for example, asking: What are the differences in the way the respondents answered this specific question? What is the main idea that this category expresses? Categories connected to themes two and three were then constructed: 2.1: Students' digital habits related to in-class activities; 2.2: Students' digital habits related to Teacher Training Practice (TTP); 3.1: Interaction knowledge; 3.2: Presentation knowledge; 3.3: Professional knowledge for the future.

Step 4: A quantitative analysis of the qualitative data was done by counting the number of unique respondents who referred to a specific answer or theme. This was not used for statistical analysis, but it revealed general patterns in the data. This methodological approach identified content related to 'Students' experiences of how their digital habits are developed during their education'.

\section{Findings}




\section{Theme 1: Students' digital habits}

The first two questions in the questionnaire focus on the students' digital habits in their spare time. In the answers to the first question the students specified a range of programme and digital forums that they participate in during their spare time (see appendix 3), and it becomes obvious that Facebook is the most popular media used. Instagram and Snapchat (apps for taking and sharing photos and videos) come as second and third. The answers to question 2 show that most students in the questionnaire have been active online for approximately ten years, but the use ranges from approximately two years up to almost 20 years of activity.

The third question in the questionnaire was two-fold: about the frequency of participation and about the roles in participation (see appendix 1). The answers indicate that all students are participants in one way or another in digital practices every day. The difference is related to frequency and type of activity. We asked them to consider if they were participants by watching/reading/listening/taking part of/updating information, etc., which we labelled as passive participation; or participants by commenting/writing/ uploading material/playing, etc., which we labelled as active participation. The results show that more students are active as passive participants each day than active participants. Among the students who answered that they participate actively (by commenting/writing/uploading material/playing/etc.), the frequency of the activity ranges from every day to once a month.

\section{Theme 2: Students' experience of how their digital habits are used in their studies in higher education}

In questions 4 and 5 (see appendix 1), the students were asked to describe the connection between their digital habits during their spare time and their education. In question 4 they were asked to answer if they think that there is any connection between these two and if the answer was 'yes', they were asked to describe the type of connection. If the answer was 'no' they were asked to formulate what was missing for such a connection to be made. Additionally, in question 5 they were asked the ways in which their digital habits are accounted for in their education. The results show that there is a discrepancy in the experience between in-class learning and their Teacher Training Practice (TTP). The findings regarding Theme 2, presented in the participants' own words, will be organised into two categories: firstly, the students' description of the connection concerning their 
studies at the university; and secondly, the connection according to their teacher training practice (TTP).

Table 1. Answers for question 4.

\begin{tabular}{|l|l|}
\hline Connection & Student \# \\
\hline $\begin{array}{l}\text { Yes, related to campus } \\
\text { studies }\end{array}$ & $\begin{array}{l}2,3,6,7,13,14,15,17,18,19,20,22,23,24,26,27,28, \\
29\end{array}$ \\
\hline Yes, related to TTP & $1,2,4,5,6,8,10,11,12,14,16,18,21,23,25,27,29$ \\
\hline $\begin{array}{l}\text { Number of 'no' responses } \\
\text { to the question }\end{array}$ & 9 \\
\hline
\end{tabular}

The result for the main question in question set 4 , shows that 28 out of 29 students clearly stated that they saw a connection between their digital habits in their spare time and their studies. The students describe two kinds of connection. One, referred to as in-class studies, is about how the students communicate and work with tasks for study purposes. The other connection, also described below is connected to their teacher training practice. Student identification number is included with each quote.

\section{Category 2.1: Students' digital habits related to campus studies}

The students reported that, in social media, they work with tasks for classroom study purposes. They noted that they share information, thoughts and texts through Facebook. Below is an example of such a response:

Yes, I see a large connection between Facebook and my studies. I can also see a smaller connection between Twitter and my education. Facebook is actively used to share both course literature and information about courses. Also we, in the class, use it for groups for studying and for social activities that are related to the education programme. (\#27) 
Some of the students' descriptions of the connection between studies and Facebook tended towards descriptions of its function as a digital learning platform (LMS):

Task groups are often arranged and discussed via groups on Facebook or in Messenger. (\#14)

My class and me have a group on Facebook where we sometimes write. It can be questions about a date for a task to be made, class party, an examination question, et cetera (\#17)

Yes, for example we have a class group on Facebook where we sometimes discuss tasks and share interesting material. I also use it to send tasks to my friends for feedback. (\#18)

\section{Category 2.2: Students' digital habits related to Teacher Training Practice (TTP)}

Students noted that social media provide a link to sites concerning pedagogical matters:

You are, in Facebook, able to follow different sites that give you tips about teaching, that can be used during the practice or you can find examples of others' work. (\#2)

Several students revealed that, thanks to how they use devices in their free time, they acquired an insight into children's digital activities. At the same time, the students also showed appreciation for the ethical dimension:

Those apps, that I use during free time, are the same apps as the children use at school, so I can absolutely see a connection to them in my education, it is important that I think of what I post. . . . (\#4)

By being aware of Instagram and other communities, you can help the pupils in conflicts, this has helped me during TTP. (\#14)

Student \#11 reported that he/she had used the context of a computer game to explain difficult English words:

In one of our last days at teaching practice, I had to explain a few difficult English words for a pupil and he did not understand until I connected to a game that I knew 
he played and through that reference everything became totally clear for the pupil. (\#11)

\section{Theme 3: Students' experience of how their digital skills are developed during their education}

From the students' answers to question 6, it appears that the majority (17/29) believe that they develop digital skills during their education. These skills vary in terms of functionality: skills to interact and communicate with each other, skills required to present content, and a combination of these two linked to their future profession as a teacher. Thus, the answers have been arranged into three categories: Interaction knowledge, Presentation knowledge, and Professional knowledge for the future.

\section{Category 3.1: Interaction knowledge}

Findings show that students both use and develop skills in using digital tools for interaction during their education.

Skype and Google Documents have been of large use in our group work. (\#1) My digital skills are constantly evolving, much to do with the fact that education takes place digitally. Especially communication opportunities are constantly evolving between teachers, practice-teacher, classmates, et cetera (\#19)

\section{Category 3.2: Presentation knowledge}

Furthermore, several students said that they not only use different programmes for presentation, but also develop further digital skills (for presentation):

I have been trying to use Movie Maker, something I have never tried before, I also developed my skills in Word. (\#5)

Since I started studying here at university, I feel that I'm challenged in my digital use, by for example making movies, changing file type and other things that I have not done before, this I see as very positive. (\#10) 


\section{Category 3.3: Professional knowledge for the future}

Finally, the students expressed their insights about the importance of being updated concerning the digital world of today, related to their future profession as a teacher:

I get tips of many good and for me new digital tools. In my practice (TTP) I will for example use ICT inspired by teachers at the university. (\#6)

By using ICT in education, I am constantly updating and developing in my use of the digital. It is very important for me to get the opportunity to develop this, so that I can feel confident in it in order to teach later on. (\#25)

I also got tips on how to make use of games in the school world or how much source criticism is needed when searching the internet. In terms of communities, we have had numerous discussions about how Facebook or other sites affect young children and their lives. This is something that will become even more current when I complete my teacher training. (\#29)

\section{Discussion}

\section{Students' digital habits as an asset in higher education}

The presented study shows that the students are not novices in the digital environment. They have been users for an average of ten years, more as passive than active participants and mostly in a small number of programmes, typically forums. They also clearly stated that they could see a connection between their digital habits in their spare time and their digital habits in their education. This is something that in one way surprised us, since earlier studies (Buzzard et al, 2011; Kelm, 2011; Lichy, 2012) show that students' own experiences of digital practice are not considered in higher education.

The importance of communication and learning with fellow students could be explained with the need for the students to be private together without the teachers always seeing their discussions and outcomes. It could also be that the students prefer to use social media due to the teachers' lack of pedagogical and technological competence (for 
example to create a functional flow in the LMS). It has been shown that both teachers and students need support (Buzzard et al, 2011; Twidle et al, 2006). Guri-Rosenblit (2009) highlighted that '[w]ithout providing adequate infrastructure and support systems for academic faculty to utilize the wide applications of the technologies, the gap between the potential of the technologies and the reality will remain wide and profound' (p.36).

\section{Students' digital skills related to Teacher Training Practice (TTP)}

Furthermore, the students expressed that during their Teacher Training Practice they felt needed and their expertise asked for when it comes to their digital skills. Their Teacher Training Practice is an authentic arena where they act and communicate in close relation to the pupils; they construct meaning together with the pupils. In this approach to learning, knowledge is clearly conceptualised (Entwistle, 2009). According to Hilsdon (2014), 'such an approach stresses the situated nature of learning and reveals that knowledge is constructed or challenged through practice' (p.252). The students tell stories of a pragmatic use of their digital skills in their future professional arena; student \#14 (see category 2.2), says that he/she can help the pupils with conflicts in the community, which can be seen as an example of a student being a supportive asset in his/her education at the academic institution. Some students believed that they could also be a resource in, for example, the subject of English where they could use their experience of computer games to explain the meaning of difficult words. Zepke (2013) points out that quality learning could be realised when teachers and students together deal with content in pedagogically suitable ways.

The students' use of digital technology in their studies may indicate that they find that their knowing and learning become more geared towards producing competences that are relevant for the specific purpose (Säljö, 2010), at their Teacher Training Practice (TTP) in schools. Harasim (2012) argued that the twenty-first century Knowledge Age has introduced a new mind-set in society, which is related to the constructivist theory that stands in opposition to behaviourism and cognitivism. She implies that we are 'active creators of our own knowledge, reconciling our previous ideas as we encounter new experiences and information' (p.12). 


\section{Development of students' digital skills by digital practice in higher education} As mentioned above, the students in this study were digital users with digital habits and skills even before they entered the studies. Despite this, they state that they still develop their digital skills during their teacher education programme. However, there is a clear difference in what they already know and what they learn during their education. They are already users of social media: firstly, of Facebook, Instagram and Snapchat; and secondly, for example, of different computer programmes for gaming and webpages for blogging and e-commerce. The knowledge that they develop in higher education is of another kind. The findings show that they develop three different kinds of digital skills at university: interaction, presentation, and professional knowledge for the future. During their teacher education programme, the students have learnt different digital programmes (such as PowerPoint, Word, Google Docs and programmes for making videos) both for educational and future professional purposes. This is in contradiction to Chen's findings (2008) who stated that the teachers (in higher education) use the technology for support of teaching only.

In addition, findings show that students during their teacher training programme also develop deeper knowledge in areas connected to their already familiar digital habits and skills, as well as an awareness of the crucial need for a critical and ethical perspective on young people's exposure to the digital environment. A consequence of this is that learning and cognitive skills must be understood in relation to the cultural artefacts (Säljö, 2010) people are surrounded with.

\section{Conclusions and implications}

How can higher education face the fact that some students might think that their mobile phone is half their brain (teenager in Prensky, 2009)? The technology 'is a major part of everyday life and they are comfortable with using the different applications simultaneously and collaboratively' (Currant, Currant \& Hartley, 2011, p.218). Students are willing to experiment with contemporary tools if the possibility is given to them and there is support available (Buzzard et al, 2011). How can higher education arrange learning situations similar to authentic practical contexts where students are able to use their digital habits and skills with the purpose of developing these within their future profession? One obstacle might be that higher education has rather specific conditions where learning outcomes are defined in curricula focused on goals. Resources in terms of time, teachers, and classrooms are predefined and fixed. There is a resistance in higher education to try 
new ways of learning, even if these ways are accepted outside the academic world (Kelm, 2011 , p.2). How can the conditions in this specific framework be negotiated (Avery \& Wihlborg, 2013) to engage students to be active participants in their own learning? In relation to education it is important how we frame the discussion about technology in relation to education (Herring, Koehler and Mishra, 2016). This study can be seen as a contribution to that discussion. Furthermore, this study can be an inspiration for future studies on the topic as well as for supporting the practice within teacher training programmes, in how to integrate students' everyday technology skills within higher education. Even though this is a small scale study in a purely Swedish context, we think that higher education needs to find ways to acknowledge students, with their different experiences of the digital world, as resources, hence it has global relevance.

\section{References}

Adams Becker, S., Cummins, M., Davis, A., Freeman, A., Hall Giesinger, C. and Ananthanarayanan, V. (2017) NMC Horizon Report: 2017 Higher Education Edition. Austin, Texas: The New Media Consortium.

Alnaim, F. (2015) 'The Case Study Method: Critical Reflection', Global Journal of Human social Science: A. Arts \& Humanities - Psychology, 15(7). Available at https://globaljournals.org/GJHSS Volume15/4-The-Case-Study-Method-CriticalReflection.pdf (Accessed: 26 February 2019)

Avery, H. and Wihlborg, M. (2013) 'Teachers' interpretation of Bildung in practice: examples from higher education in Sweden and Denmark', Journal of Learning Development in Higher Education, Issue 5, pp.1-20.

Beaudoin, M.F. (ed.) (2006) Perspectives on higher education in the digital age. New York: Nova Science Publishers, Inc.

Buzzard, C., Crittenden, V.L., Crittenden, W.F. and McCarty, P. (2011) 'The use of digital technologies in the classroom: A teaching and learning perspective', Journal of Marketing Education 33(2), pp.131-139. 
Carli, V., Hoven, C. W., Wasserman, C., Chiesa, F., Guffanti, G., Sarchiapone, M., Apter, A., Balazs, J., Brunner, R., Corcoran, P., Cosman, D., Haring, C., losue, M., Kaess, M., Kahn, J. P., Keeley, H., Postuvan, V., Saiz, P., Varnik, A., Wasserman, D. (2014) 'A newly identified group of adolescents at 'invisible' risk for psychopathology and suicidal behavior: findings from the SEYLE study', World Psychiatry: Official Journal of the World Psychiatric Association (WPA) 13(1), pp.78-86.

Chen, C. (2008) 'Why do teachers not practice what they believe regarding technology integration?', The Journal of Educational Research 102(1), pp.65-75.

Currant N., Currant B. and Hartley, P. (2011) 'Defining and Supporting the New Digital Students', in Hartley, P., Hilsdon, J., Keenan, C., Sinfield, S. and Verity, M. (eds.), Learning Development in Higher Education. New York: Palgrave Macmillan.

Entwistle, N. (2009) Teaching for understanding at university: deep approaches and distinctive ways of thinking. Houndmills, Basingstoke: Palgrave Macmillan, 2009.

Guri-Rosenblit, S. (2009) Digital Technologies in Higher Education: Sweeping Expectations and Actual Effects. New York: Nova Science Publishers, Inc.

Harasim, L.M. (2012) Learning theory and online technologies. New York: Routledge.

Herring, M.C., Koehler, M.J. and Dona, P. (ed.) (2016) Handbook of technological pedagogical content knowledge (TPCK) for educators. 2nd edn. New York: Routledge.

Hilsdon, J. (2014) 'Peer learning for change in higher education', Innovations in Education and Teaching International 51(3), pp.244-254.

Jain, A. and Dutta, D. (2018) 'Millennials and Gamification: Guerilla Tactics for Making Learning Fun', South Asian Journal of Human Resources Management 6(1), pp.116. 
Kelm, Orlando R. (2011) 'Social media: It's what students do', Business Communication Quarterly, 74(4), pp.505-520.

Knobel, M. and Lankshear, M. (2007) 'Sampling "the New" in New Literacies', in Knobel, M. and Lankshear, C. (ed.), A new literacies sampler. New York: P. Lang.

Laurillard, D. (2012) Teaching as a design science: building pedagogical patterns for learning and technology. 3rd edn. London: Routledge.

Lichy, Jessica (2012) 'Towards an international culture: Gen Y students and SNS?' Active Learning in Higher Education 13(2), pp.101-116.

Liu, C. (2018) 'Social media as a student response system: New evidence on learning impact', Research in Learning Technology 26. Available at https://doi.org/10.25304/rlt.v26.2043 (Accessed: 22 November 2018)

Moos, D. C. and Honkomp, B. (2011) 'Adventure Learning: Motivating Students in a Minnesota Middle School', Journal of Research on Technology in Education 43(3), pp.231-252.

Neumann, M.M. and Neumann, D.L. (2013) 'Touch screen tablets and emergent literacy', Early Childhood Education Journal 42(4), pp.231-239. Available at https://pdfs.semanticscholar.org/48ab/b4f35949ea9561f9fddc29d71472f9bc047d.pd f (Accessed: 22 November 2018)

O'Brien, K. (2010) 'What happened to studying?', The Boston Globe. Available at: http://www.boston.com/bostonglobe/ideas/articles/2010/07/04/what happened to s tudying/ (Accessed: 22 November 2018)

OECD (2016) 'PISA 2015 Results (Volume I): Excellence and Equity in Education', Paris: PISA, OECD Publishing. Available at https://doi.org/10.1787/9789264266490-en (Accessed: 22 November 2018) 
Prensky, M. (2009) 'H. Sapiens Digital: From Digital Immigrants and Digital Natives to Digital Wisdom', Innovate: Journal Of Online Education 5(3). Available at https://nsuworks.nova.edu/cgi/viewcontent.cgi?article=1020\&context=innovate (Accessed: 12 March 2019)

Rogers, D.L. (2000) 'A Paradigm Shift: Technology Integration for Higher Education in the New Millennium', Educational Technology Review 13 (Spr-Sum), pp.19-27,33. Available at http://citeseerx.ist.psu.edu/viewdoc/download?doi=10.1.1.196.5141\&rep=rep1\&type =pdf (Accessed: 22 November 2018)

Säljö, R. (2010) 'Digital tools and challenges to institutional traditions of learning: technologies, social memory and the performative nature of learning', Journal of Computer Assisted Learning 26(1), pp.53-64.

Taylor-Powell, E. and Renner M. (2003) 'Analyzing Qualitative Data', University of Wisconsin-Extension. Available at:

http://blog.soton.ac.uk/dissertation/files/2013/09/Taylor-Powell-2003.pdf (Accessed: 31 May 2017).

Trucano, M. (2005) 'Knowledge Maps: ICT in Education', World Bank: The Information for Development Program. Available at http://www.infodev.org/infodevfiles/resource/InfodevDocuments 8.pdf (Accessed: 17 May 2017)

Twidle, J., Sorensen, P., Childs, A., Godwin, J. and Dussart, M. (2006) 'Issues, challenges and needs of student science teachers in using the internet as a tool for teaching', Technology, Pedagogy and Education 15(2), pp.207-221.

Yin, R.K. (1984) Case Study Research: Design and Methods. Beverly Hills, CA: Sage Publications.

Yin, R. (1994) Case study research: Design and methods. 2nd edn. Beverly Hills, CA: Sage Publishing. 
Zepke, N. (2013) 'Threshold Concepts and Student Engagement: Revisiting Pedagogical Content Knowledge', Active Learning in Higher Education 14(2), pp.97-107.

\section{Author details}

Eva Hansson is a Lecturer in Primary School Teacher Programme and a Pedagogical Developer at the Centre for Educational Development at Halmstad University.

Jeanette Sjöberg is a Senior Lecturer in Pedagogy and Head of the Centre for Educational Development at Halmstad University.

\section{Appendix 1}

\section{Questionnaire}

Please answer the following six questions:

1. Which different digital practices (e.g. forums, online communities, interactive on- and offline gaming), do you participate in and use, in your spare free time?

2. For how long (approximately) have you been active in digital practices during your free time?

3. How often are you active / do you participate in digital practices? Specify the activity relative to:

a) How often you participate by watching / reading / listening / taking part of / updating /information /et cetera? And

b) How often you participate by commenting/writing/uploading material/playing/et cetera?

4. Do you see any connection between your digital habits in spare time and your education?

If yes, how can such a connection be described? If no, what is missing for such a link to be made?

5. In which ways are your digital habits accounted for in your education (practice, selfstudy, campus)? 
6. In what ways are your digital habits developed through your education (practice, selfstudy, campus)?

Number your answers as above.

You answer individually and your classmates can not see your answers.

\section{Appendix 2}

Translated from the Swedish document that was sent to the participants

Research ethical principles

We will take into account the research ethical principles that have to do with the requirement for: information, consent, confidentiality and utilization.

Read more in the attached document ("Research ethics principles") about what these mean! In short, we want to make it clear that your participation is entirely voluntary!

You can, if you want to cancel your participation at any time and you associate yourself with nothing.

You can request more information about the project and your participation when you want. You can also choose not to participate at all.

If you choose to participate, we guarantee that we only use your statements in the research context, where your personal data will be anonymised.

Contact information, researchers:

Jeanette Sjöberg: jeanette.sjoberg@hh.se

Annika Elm Fristorp: annika.elm_fristorp@hh.se

Eva Hansson: eva.hansson@hh.se

\section{Appendix 3}


Answers to question 1: Which different digital practices (eg. forums, online communities, interactive on- and offline gaming), do you participate in and use, in your spare free time?

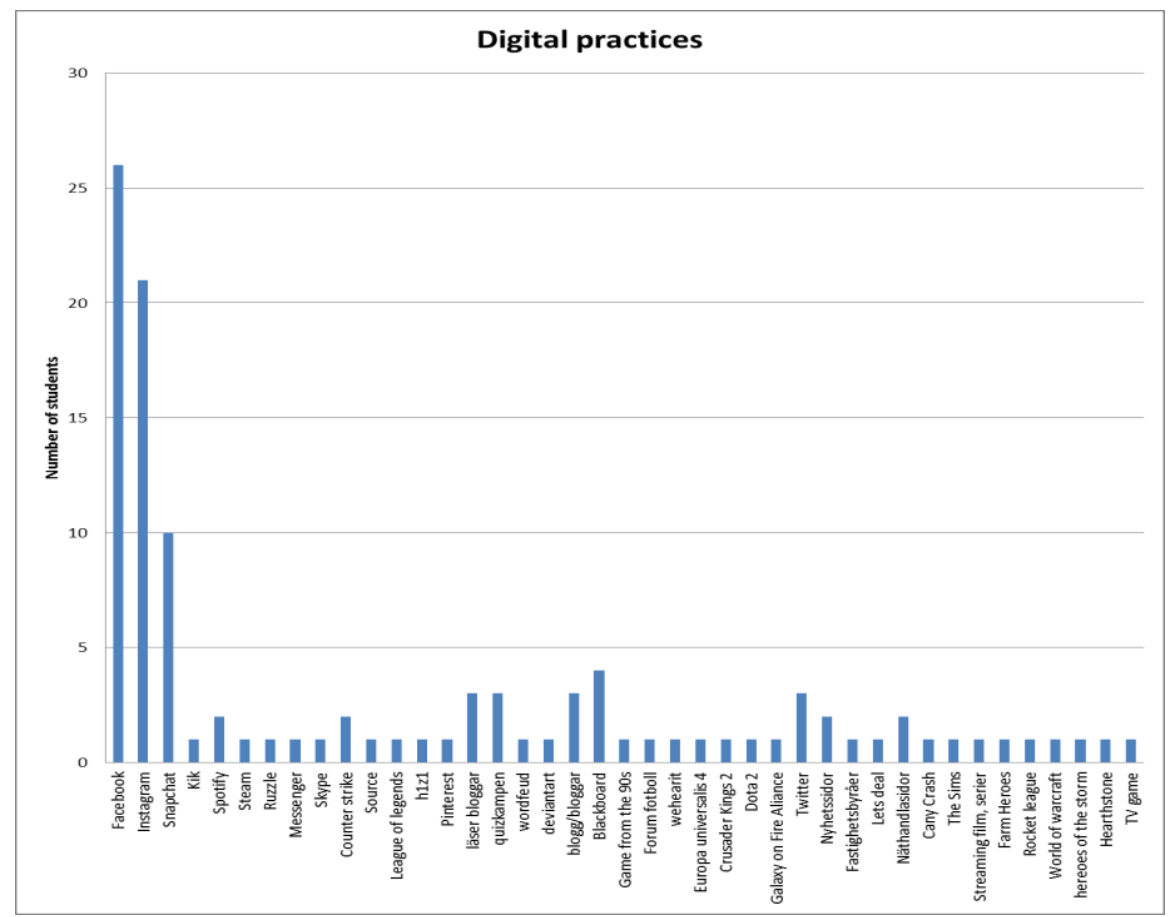

